\title{
Shear Wave Experiments at the U. S. Site at the Grimsel Laboratory
}

\author{
Ernest L. Majer and John E. Peterson Jr. \\ Earth Sciences Division \\ Lawrence Berkeley Laboratory \\ University of California \\ Berkeley, California 94720
}

\author{
Peter Blümling and Gerd Sattel \\ Swiss National Cooperative for the Storage of Nuclear Waste \\ Baden, Switzerland
}

July 1990

This work was supportca by the Manager, Chicago Operations, Repository Technology Program, Repository Technology and Transportation Division, of the U.S. Depariment of Energy under Contract No. DEAC03-76SF00098 and hy the Swiss National Cooperative for the Storage of Nuclear Waste (NAGRA).

\section{MASTER}

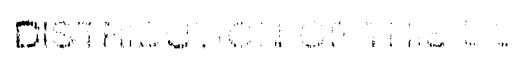




\section{Preface}

This report is one of a series documenting the results of the Nagra-DOE Cooperative (NDC-I) research program in which the cooperating scientists explore the geological, geophysical, hydrological, geochernical, and structural effects anticipated from the use of a rock mass as a geologic repository for nuclear waste. This program was sponsored by the U. S. Department of Energy (DOE) through the Lawrence Berkeley Laboratory (LBL) and the Swiss Nationale Genossenschaft flur die Lagerung radioaktiver Abfalla (Nagra) and concluded in September 1989. The principal investigators are Jane C. S. Long, Ernest L. Majer, Karsten Pruess, Kenzi Karasaki, Chalon Carnahan and Chin-Fu Tsang for LBL and Piet Zuidema, Peler Bllımling, Peter Hufschmied and Stratis Vomvoris for Nagra. Other participants will appear as authors of the individual reports. Technical reports in this series are listed below.

1. Determination of Fracture Inflow Parameters with a Borehcle Fluid Conductivity Logging Method by Chin-Fu Tsang, Peter Hufschmied, and Frank V. Hale (NDC-1, L,BL-24752).

2. A Code to Compute Borehole Fluid Conductivity Profiles with Multiple Feed Points by Frank V. Hale and Chin-Fu Tsang (NDC-2, LBL-24928; also NTB 88-21).

3. Numerical Simulation of Alteration of Sodium Bentonite by Diffusion of Ionic Groundwater Components by Janet S. Jacobsen and Chalon L. Carnahan (NDC-3, LBL-24494).

4. P-Wave Imaging of the FRI and BK Zones at the Grimsel Rock Laboratory by Ernest L. Majer, John E. Peterson Jr., Peter Blumling, and Gerd Sattel (NDC-4, LBL-28807).

5. Numerical Modeling of Gas Migration at a Proposed Repository for Low and Intermediate Level Nuclear Wastes at Oberbauenstock, Switzerland by Karsten Pruess (NDC-5, LBL-25413).

6. Áralysis of Well Test Data from Selected Intervals in Leuggern Deep Borehole - Verification and Application of PTST Method by Kenzi Karasaki (NDC-6, LBL-27914).

7. Shear Wave Experiments at the U. S. Site at the Grimsel Laboratory by Entest L. Majer, John E. Pete'son Jr., Peter Bllumling, and Gerd Sattel (NDC-7 LBL-28808).

8. The Application of Moment Methods to the Analysis of Fluid Electrical Conductivity Logs in Boreholes by Simon Loew, Chin-Fu Tsang, Frank V. Hale, and Peter Hufschmied (NDC-8, LBL28809).

9. Numerical Simulation of Cesium and Strontium Migration through Sodium Bentonite Altered by Cation Exchange with Groundwater Components by Janet S. Jacobsen and Chalon L. Camahan (NDC-9, LBL-26395).

10. Theory a.d Calculation of Water Distribution in Bentonite in a Thermal Field by Chalon L. Carnahan (NDC-10, LBL-26058).

11. Prematurely Terminated Slug Tests by Kenzi Karasaki (NDC-11, LBL-27528).

12. Hydrologic Characterization of Fractured Rocks -- An I erdisciplinary Methodology by Jane C. S. Long, Emest L. Majer, Stephen J. Martel, Kenzi Karasaki, John E. Peterson Jr., Amy Davey, and Kevin Hestir, (NDC-12, LBL-27863).

13. Exploratory Simulations of Multiphase Effects in Gas Injection and Ventilation Tests in an Underground Rock. Laboratory by Stefan Finsterle, Erika Schlueter, and Karsten Pruess (NDC-13, LBL. 28810).

14. Joint Seismic, Hydrogeological, and Geomechanical Investigations of a Fracture Zone in the Grimsel Rock Laboratory, Switzerland by Ernest L. Majer, Larry R. Myer, John E. Peterson Jr., Kenzi Karasaki, Jane C. S. Long, Stephen J. Mantel, Peter Blumling, and Stratis Vomvoris (NLC-14, LBL27913).

15. Analysis of Hydraulic Data from the MI Fracture Zone at the Grimsel Rock Laboratory, Swituerland by Amy Davey, Kenzi Karasaki, Jane C.S. Long, Martin Landsfeld, Antoine Mensch, and Stephen J. Martel (NDC-15, LBL-27864).

16. Use of Integrated Geologic and Geophysical Information for Characterizing the Structure of Fracture Systems at the US/BK Site, Grimsel Laboratory, Switzerland by Stephen J. Marel and John E. Feiersun jt. (TNDC-10, LDL-279ia). 


\section{Table of Contents}

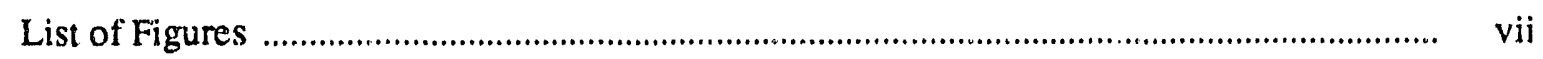

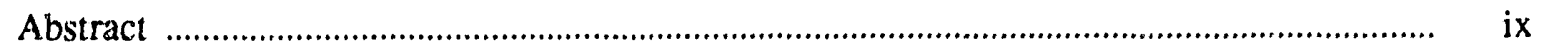

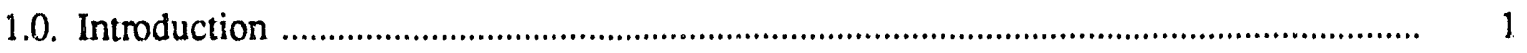

2.0. Shear Wave Studies at the U. S. Site …..................................................................... 5

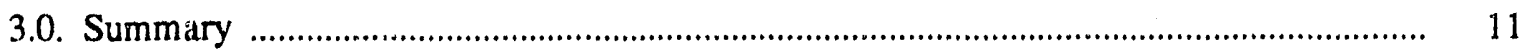

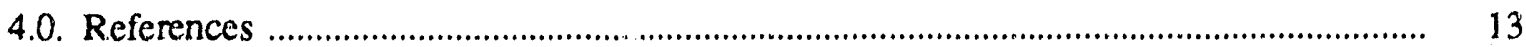




$$
\text { -viifuiii }
$$

\section{List of Figures}

Page

Figure 2.1. Layout of the U. S. zone boreholes in relation to the BK zone.

Figure 2.2. P-wave tomogram of area between USO01 and USO02, the velocity interval is 5.0 to $5.5 \mathrm{~km} / \mathrm{sec}$ (light to dark).

Figure 2.3. S-wave tomogram of area between USO01 and USO02, the velocity interval is 3.2 to $4.0 \mathrm{~km} / \mathrm{sec}$ (light to dark).

9

Figure 2.4. A tomogram of the Vp/Vs ratio's between USO01 and USO02, the interval is from 1.5 to 2.0 (light to dark). 
$-i x-$

\begin{abstract}
Data from a crosshole tomographic survey in the Underground Scismic (U. S.) site at the Nagra Grimsel test facility in Switzerland was successfully reprocessed to enhance the S-wave arrivals. The results indicate that in a saturated granite $\mathrm{Vp} / \mathrm{Vs}$ ratios approach 2.0 in the fractured rock. These results indicate that S-wave data would be very useful for fracture detection, especially in detecting thinner fractures.
\end{abstract}




\subsection{Introduction}

As part of the United States Department of Energy (USDOE) cooperative project with the National Cooperative for the Storage of Radioactive Waste (Nagra) of Switzerland, there have been a series of studies carried out at the Nagra underground test facility at Grimsel. The Grimsel test facility is several 3.5 meter diameter tunnels excavated with a tunnel boring machine in the southem Swiss Alps. The rock type is granitic, although there is a large variation in the granitic fabric throughout the facility. The work described here was the first phase of a multiyear project to evaluate and develop seismic imaging techniques for fracture detection and characterization for the use in siting underground nuclear waste facilities.

The problem of adequate fracture detection and characterization is essential to the accurate modeling of the hydrologic and geomechanical behavior of any underground nuclear waste repository. Fracture properties can be directly measured at the surface and underground openings, but because of the large variation in the geometry of fracture sets, it is unlikely that one can rely on the direct interpolation of structural information between boreholes for proper fracture characterization. Although there may be many fractures, or sets of fractures, the relative geomechanical or hydrologic contribution of the fractures may vary widely. Therefore, there is a crucial need to have techniques for fracture detection and characterization between boreholes. The problem of detection is very different from characterization. Detection may only involve the confirmation of the existence of fractures. Characterization ideally would be not only be the detection of the fractures, but would also define such parameters as orientation, density, aperture, degree of connection, and infilling material. In addition to the problem of characterization of a potential under-

ground repository site, there is the problem of having a means for adequate performance confirmation. In order to address these problems one naturally turns to geophysical methods for solutions, i.e., the seismic and electrical methods. 
As applied on a large scale to a repository environme.tt the most likely burehole seismic method would be the multi-offset/multi-source Vertical Seismic Profiling (VSP) from the surface and crosshole techniques in the underground workings. By performing a tomographic analysis of the VSP and crosshole data from multiple offsets and azimuths, it may be possible to map the fracture content and structure. This data could then be used in hydrologic or geomechanical models of fracture networks to study the behavior of the rock mass. Seismic methods would then be used to provide a method for extrapolating fracture characteristics observable at the borehole walls and underground workings to the entire repository block, thus providing a more complete data set to characterize the overall hydrologic and geologic parameters.

Fracture detection using P- and S-waves in VSP studies is not a new idea, (Stewart et al., 1981). It is becoming increasingly apparent, however, that to utilize the full potential of VSP, 3component data should be acquired. Crampin has pointed out the importance of using 3component data in VSP work, particularly for fracture detection (Crampin, 1978, 1981, 1984a, 1984b, 1985). These authors and others have pointed out the phenomenon of shear wave splitting and the anisotropy effects of SH-versus the SV- waves in addition to P-versus S-wave anisotropy (Leary and Henyey, 1985). In addition to Crampin's theoretical work on shear wave splitting $(1978,1985)$ there has been some recent laboratory (Hopkins et al., 1987) and theoretical work Schoenberg $(1980,1983)$ which explains seismic anisotropy in terms of fracture stiffiness. The fracture stiffness theory differs from Crampin's theory in that at a fracture, or a non-welded interface, the displacement across the surface is not required to be continuous as a seismic wave passes. The only boundary condition in the solution to the wave equation is that the stress must remain continuous across an interface. This displacement discontinuity is taken to be linearly related to the stress through the stiffness of the discontinuity.

The implication of the fracture stiffness theory is that for very thin discontinuities, for example fractures, there can be significant effect upon the propagation of a wave. Usually one thinks of seismic resolution in terms of wavelength as compared to the thickness and lateral extent of a bed or nther feature. In the stifiness theory the lateral extent is still important, but if 
the fracture stiffness is small enough the thickness of the feature can be much much less than the seismic wavelength. The effect should be even more pronounced in an unsaturated environment, such as at the DOE site at Yucca Mnuntain, Nevada, because the stiffness of an unsaturated fracture is less than that of a saturated fracture. Thus for any given size of fracture the lower limit of fracture detectability in an unsaturated fracture will be smaller than if the fracture is saturated. Alternatively, if the fractures are fairly uniform, it may be possible to map isolated saturated zones or perched water.

This stiffness theory is also attractive from several other points of view. Schoenberg $(1980,1983)$ shows that the ratio of the velocity of a shear waves perpendicular and parallel to a set of stiffness discontinuities is a function of the spacing of the discontinuities as well as the stiffness. Thus, given the stiffness and the velocity anisotropy, one may be able to determine the average fracture spacing or density. Or, aitematively, given independent information on fracture density, one could determine the fracture stiffness and hopefully relate this stiffness to actual fracture properties such as discriminating between fillet and open fractures or hopefully hydraulic conductivity. In any case, there is sufficient reason to expect fracture content and properties to be reflected in the velocity, amplitude, and polarization of the seismic waves. 


\subsection{Shear Wave Studies at the U. S. Site}

A study in the USDOE-Nagra work involved reprocessing a portion of preexisting cross hole seismic data that was obtained by the Swiss at the Underground Stirmic (U. S.) site in the Grimsel test facility. The U. S. site is located near the BK Zone (see Figure 1). The U.S. site was designated as the area located between three 150 meter long sub-horizontal holes drilled downward at 15 degree angles from the main tunnel. The three holes are BOUS85.001, BOUS85002, and BOUS85.003, see Figure 2.1. Hole 1 is the northern most hole which is 75 meters from hole 2 and 225 meters fiom hole 3 . In addition to these holes there was a series of shallow $(50 \mathrm{~cm})$ small diameter holes drilled 2.5 meters apart in the tunnel walls to emplace sensors. Therefore, in the US area thers was a 3-sided tomographic survey carried out to map large scale features in this area. The data were taken at 2.5 meter intervals along the tunnel and at 2.5 meter intervals in the bore holes. Sinall explosive charges were used as sources in the long boreholes in field 3 only. A hammer was used as a source on the tunr al walls.

Prior to processing of the data for S-wave information, the Swiss had processed the P-wave information to image the U.S. area. The result of this work was P-wave tomograms of the area between USOO1 and USO02, USOO2 and USO03, and between USOO1 and USO03. However, in some of the ciata there was an indication of usable shear wave data, although both explosive and hammer sources had been used in the boreholes, and on the tunnel walls. Therefore, the raw data

were obtained and processed to enhance the shear wave arrivals. The data were collected on two component receivers, parallel and perpendicular to the boreholes.

The processing sequence was to first filter the P-wave and tube wave energy from the data. This was done almost on an individual basis for each receiver group. The dominant $S$-wave frequency was about half of the P-wave energy, i.e. 500 hertz versus 1000 hertz, therefore simple bandpass filtering was done on most of the data. More sophisticated techniques were applied to 


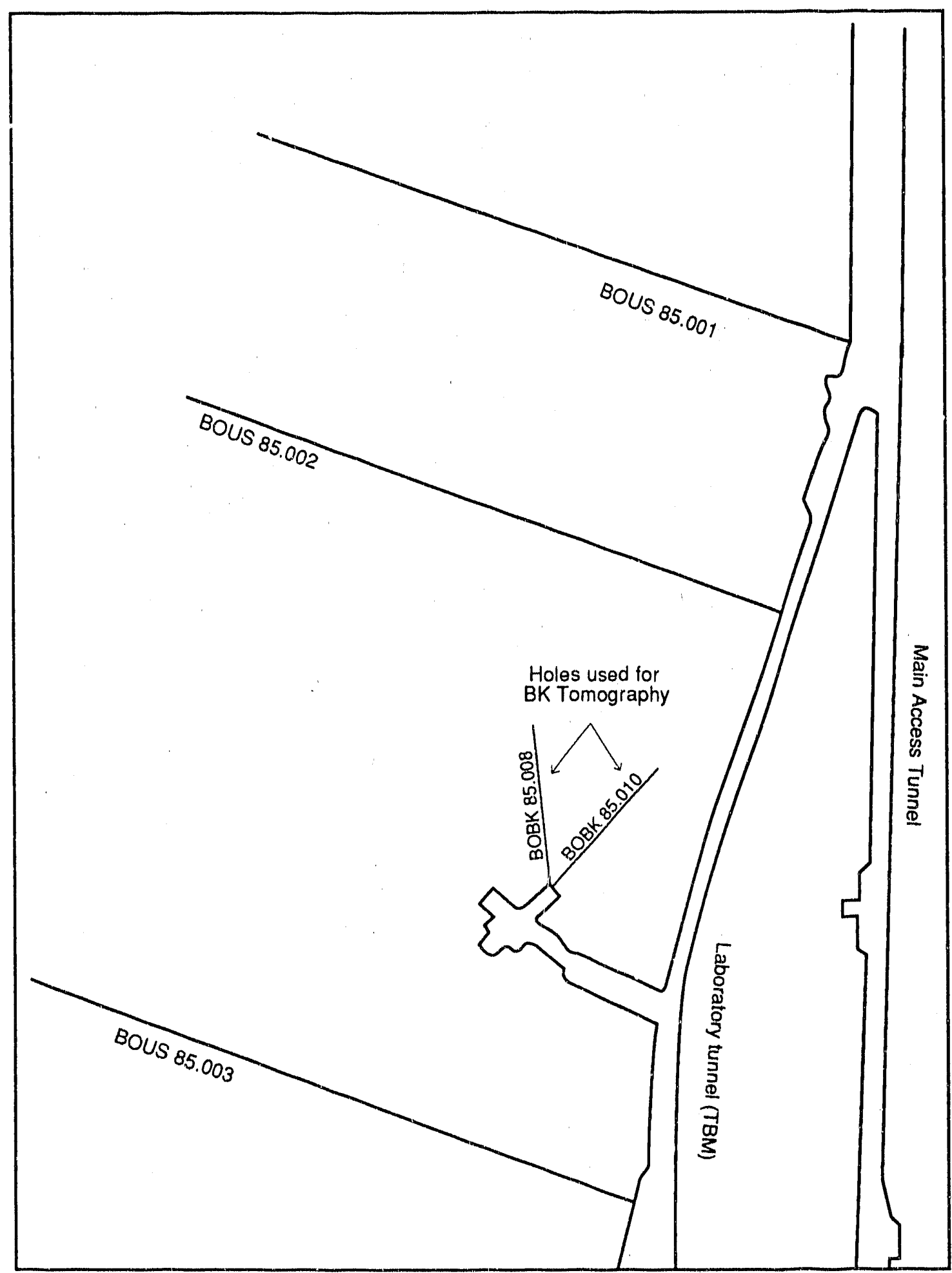

Modified XBL 8911-7897

T.L.L. Illus.88 (Lisette)

Figure 2.1. Layout of the U.S. zone boreholes in relation to the BK zone. 
the data such as coherency filtering and frequency-wavenumber (FK) analysis to enhance the Swave arrival times, however no "cook book" approach for the entire data set could be determined. After the best data set was obtained all S-wave times were picked by hand from expanded paper record sections, the scale was 10 inches per second and 3 traces per inch. This gave timing precision to better than 0.05 milliseconds. After the data were picked the data were inverted for a tomographic image. Only the data between USO01, and USO02 were of sufficient quality to have enough arrivals to be inverted for S-wave information. Shown in Figures 2.2 and 2.3 are the Pwave tomograms and S-wave tomogram for the same ray set, respectively. In general the same features show up, but are slightly more pronounced in the S-wave data. No anisotropy corrections were done on the data. Unfortunately the amount of S-wave data were limited, as in the case of similar studies in other parts of the Grimsel facility, but these results do indicate that if one can obtain S-wave data it may provide a more focused picture of the rock. Shown in Figure 2.4 is the $\mathrm{Vp} / \mathrm{Vs}$ ratio. It interesting to note that this may be a more sensitive measure of rock properties than, using P-wave or S-wave alone. 


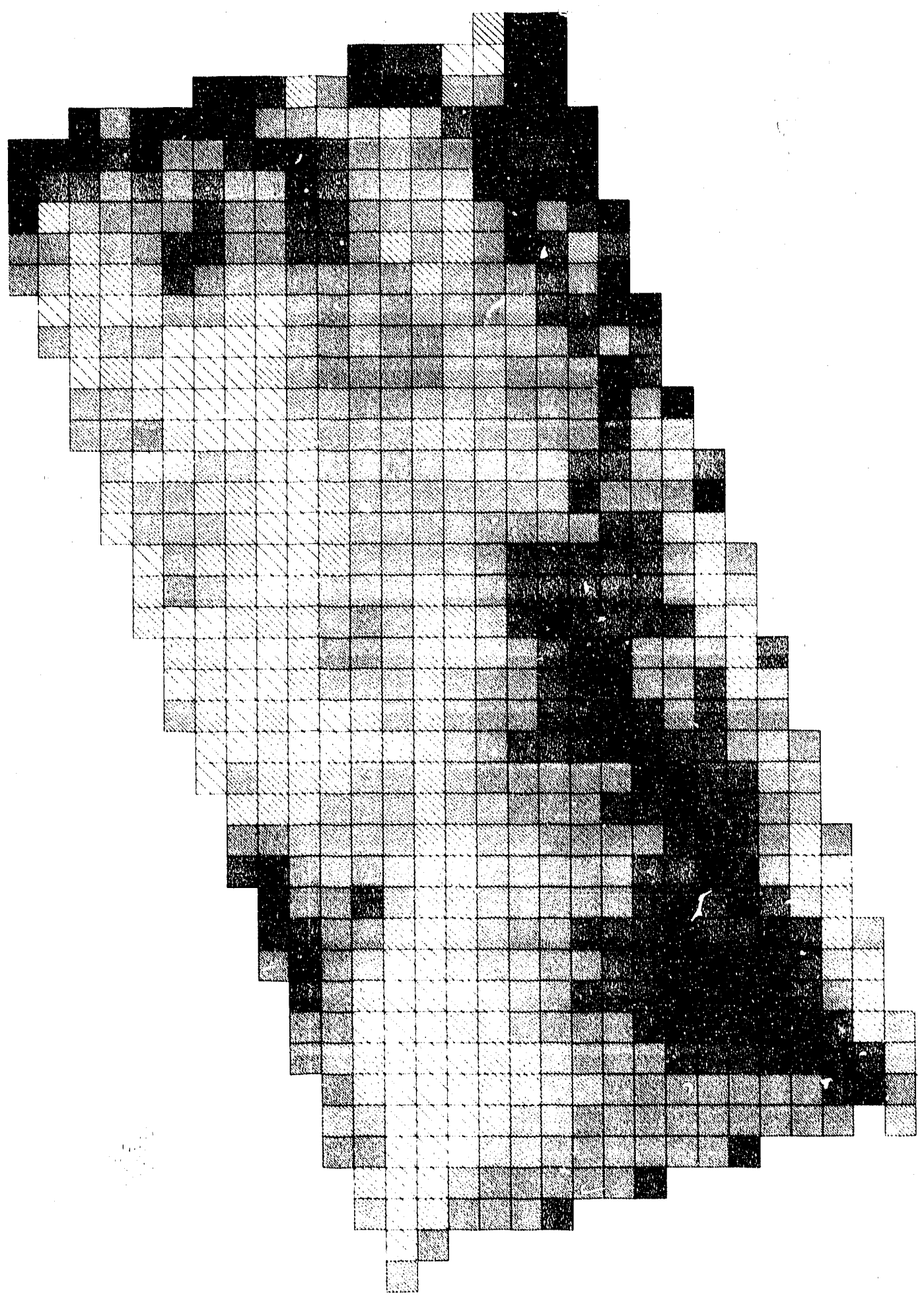

XBL. 8910.3880

Figure 2.2. P-wave tomogram of area between USO01 and USO02, the velocity interval is 5.0 to $5.5 \mathrm{~km} / \mathrm{sec}$ (light to dark). 


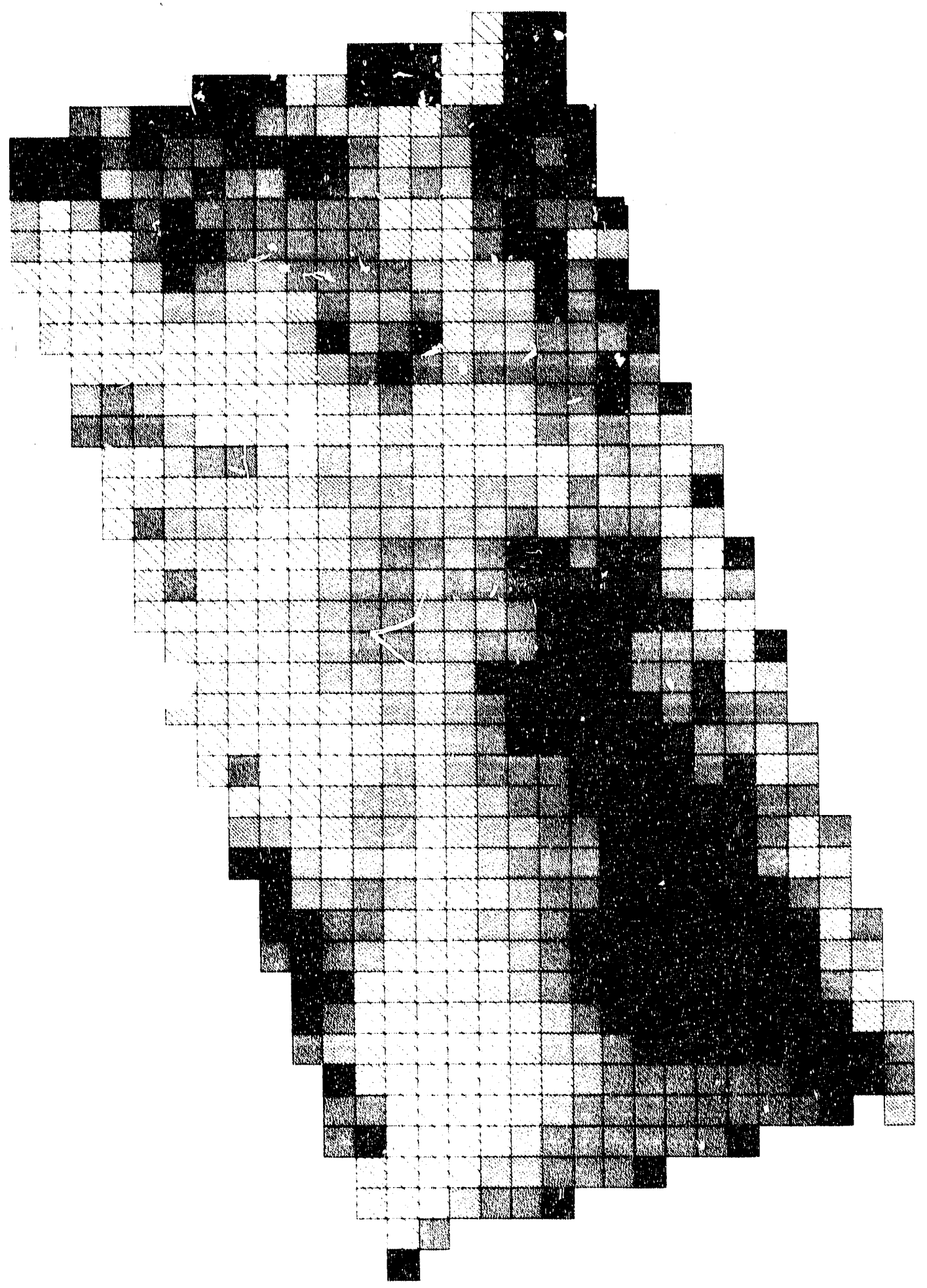

xa. $0910-3870$

Figure 2.3. S-wave tomogram of area between USOO1 and USOO2, the velocity interval is 3.2 to $4.0 \mathrm{~km} / \mathrm{sec}$ (light to dark). 


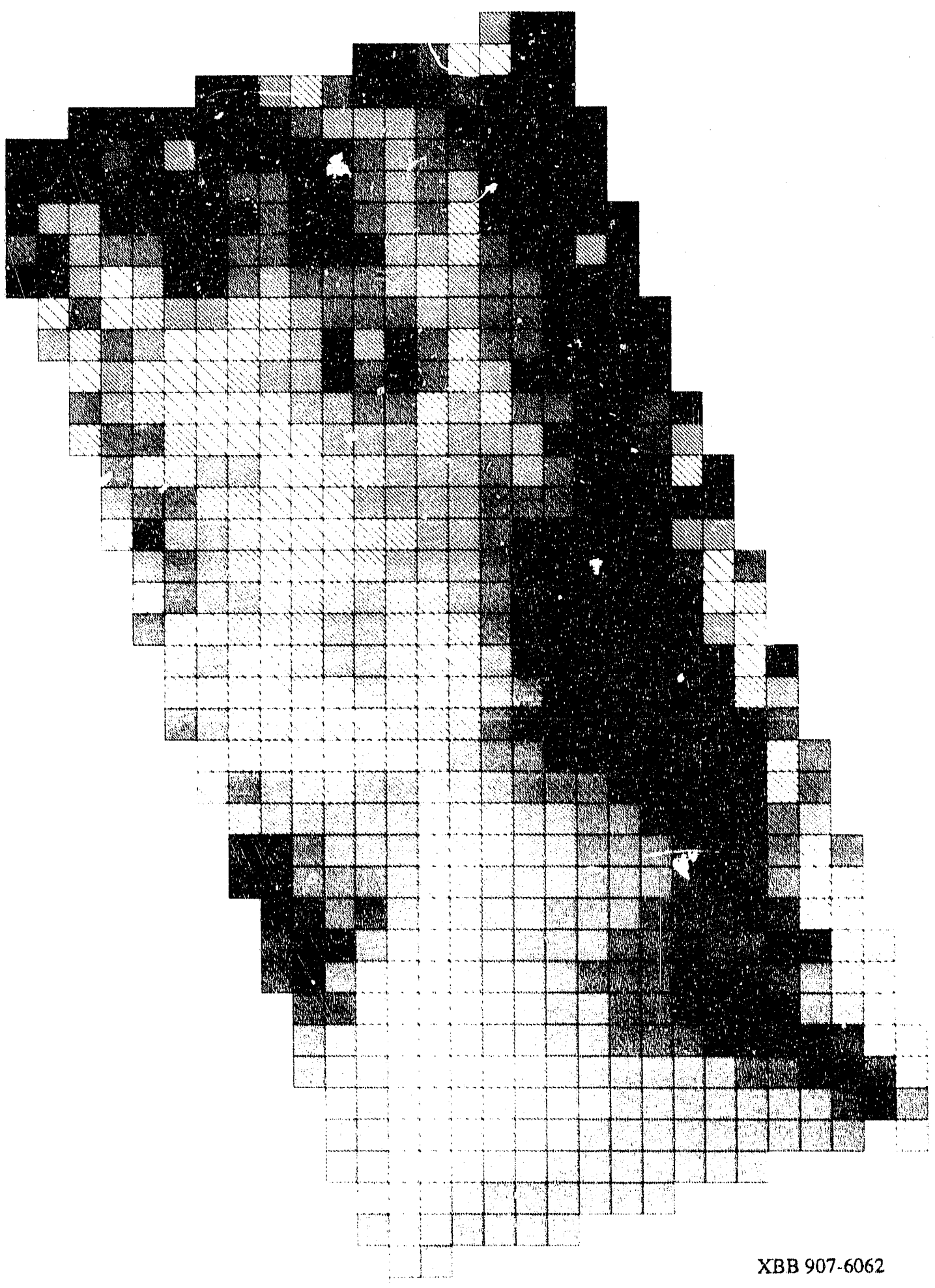

Figure 2.4. A iomogram of the Vp/Vs ratio's between USOO1 and USOO2, the interval is from 1.5 to 2.0 (light to dark). 


\subsection{Summary}

The results of tile field work to date indicate that the original premise of using $\mathrm{P}$ - and $\mathrm{S}$ waves for mapping fracture content is valid. Unfortunately there is no cook-book approach to extract S-wave data from these type of surveys. The S-wave does seem to be attenua $y d$ and scatizred from fractums more than P-waves. especially in a saturated rock as in this case. Future work should focus on using improved shear wave data for improving the resolution of the technique and for defining such parameters as fracture density and spacing. The reprocessing of the S-wave data from the U.S. site again indicated that there is a crucial need for shear wave sources that can be controlled. 


\subsection{References}

Crampin, S., 1978. Seismic-wave propagation through a cracked solid: Polarization as a possible dilatancy diagnostic, Geophys. J. Roy. Astron. Soc., 53, 467-496.

Crampin, S., 1981. A review of wave motion in anisotropic and cracked elastic-media, Wave Motion, 3, 343-391.

Crampin, S., 1984a. Effective anisotropic propagation through a cracked solid, In Crampin, S., Hipkin, R. G., and Chesnokov, E. M., eds., Proc. of the First International Workshop on Seismic An: sotropy, Geophys. J. Roy. Astron. Soc., 76, 135-145.

Crampin, S., 1984b. Anisotropy in exploration seismics, First Break, 2, 19-21.

Crampin, S. . 1985. Evaluation of anisotropy by shear wave splitting, Geophysics, 50, (1) 142152.

Hopkins, D. L., N. G. W. Cook, and L. R. Myer, 1987. Fraciure stiffiness and aperture as a function of applied stress and contact geometry, Proc. of 28th Symp. on Rock Mechanics, University of Arizona, Tucson, Arizona, June 29-July 1.

Kanasewich, E. R., 1975. Time Sequence Analysis in Geophysics, The University of Alberta Press, Edmonton, Alberta.

Leary, P. C. and T. L. Henyey, 1985. Anisotropy and fracture zones about a geothermal well from P-wave velocity profiles, Geophysics, 50, (1) 25-36.

Schoenberg, M., 1980. Elastic wave behavior across linear slip interfaces: J. Acoust. Soc. Am., 68, (5) 1516-1521.

Schoenberg, M., 1983. Reflection of elastic waves from periodically stratified media with interfacial slip, Geophys. Prosp., 31, 265-292.

Stewart, R. R., R. M. Turpening, and M. N. Toksoz, 1981. Study of a subsurface fracture zone by vertical seismic profiling, Geophys. Res. Lett., 8, 1132-1135. 

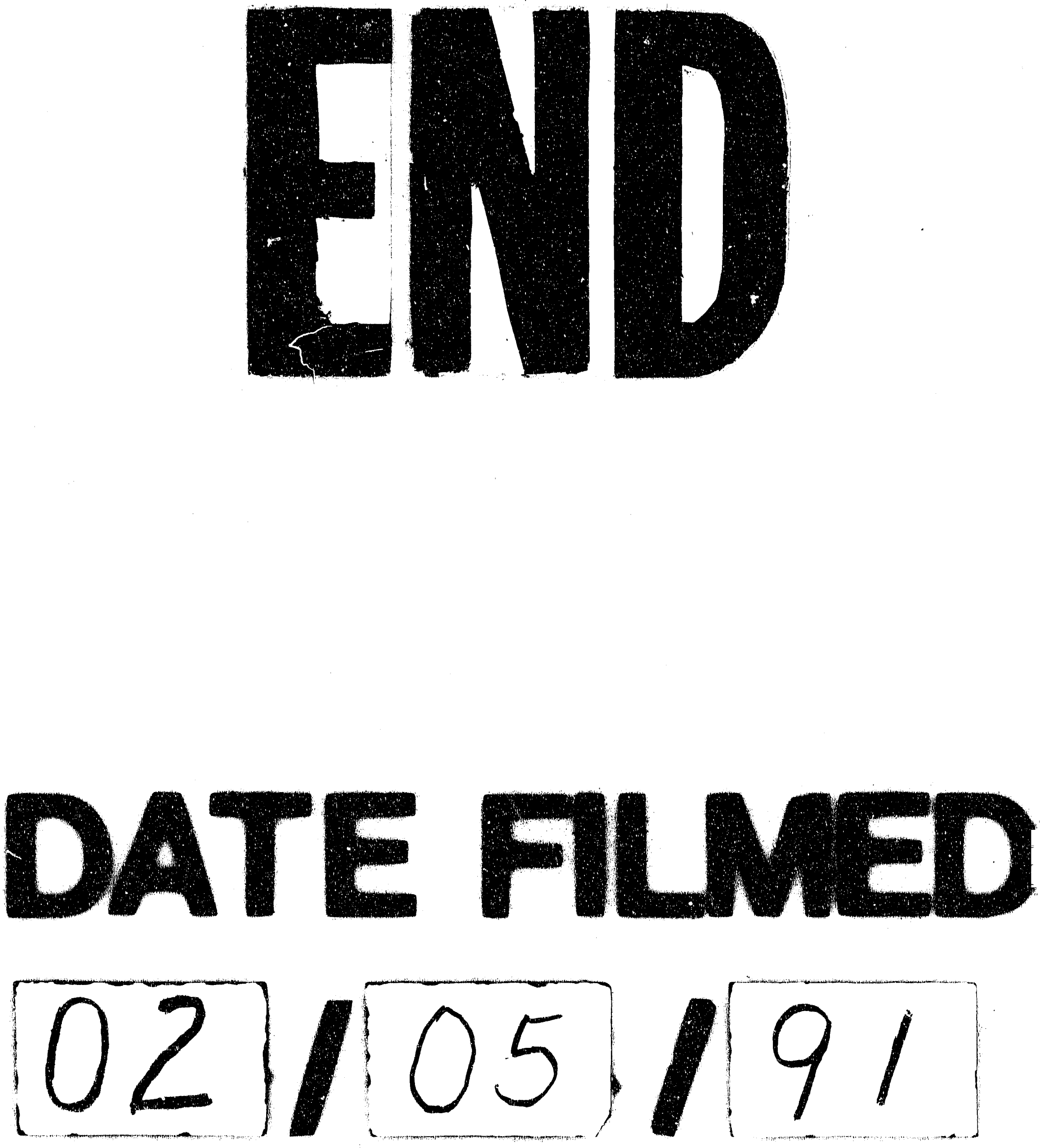
